\title{
ANALYSIS OF THE THERMAL INSULATION OF TEXTILES USING THERMOGRAPHY AND CFD SIMULATION BASED ON MICRO-CT MODELS
}

\author{
Adam K. Puszkarz*, Jarosław Wojciechowski, Izabella Krucińska \\ Institute of Material Science of Textiles and Polymer Composites, Lodz University of Technology, 116 Zeromskiego Street, 90-924 Lodz, Poland \\ ${ }^{*}$ Corresponding author. E-mail: adam.puszkarz@p.lodz.pl
}

\begin{abstract}
:
The article presents the results of an attempt to use high-resolution X-ray micro-computed tomography (micro-CT) to model the thermal insulation of clothing as one of the most important parameters affecting the heat balance between a human and his/her surroundings. Cotton knitted fabric applied in functional clothing for newborns and aramid woven fabric used in multilayer protective clothing for firefighters were the tested materials. The 3D models of real textiles based on micro-CT images were developed. Next, the models were applied to heat transfer simulations using the finite volume method. The usefulness of the models was experimentally verified using thermography with real textiles. The simulation results were consistent with the measurement results and confirmed the relationship between the thermal insulation and geometry of the textiles on the one hand and the physical parameters of the raw materials from which they were made on the other hand.
\end{abstract}

\section{Keywords:}

thermal insulation; thermography; micro-computed tomography; micro-CT; simulation; modeling; functional clothing

\section{Nomenclature}

$e-$ specific internal energy $(\mathrm{J})$

$h$ - thermal enthalpy per unit mass $\left(\mathrm{J} \cdot \mathrm{kg}^{-1}\right)$

$p$ - pressure $(\mathrm{Pa})$

Pr- Prandtl number (dimensionless)

$Q_{H}$ - heat change (released or absorbed) per unit volume $\left(\mathrm{W} \cdot \mathrm{m}^{-3}\right)$

$Q_{T}^{\text {out }}$ - heat radiation leaving a radiative surface $\left(\mathrm{W} \cdot \mathrm{m}^{-2}\right)$

$Q_{T}{ }^{\text {in }}$ - incident thermal radiation arriving at a surface $\left(\mathrm{W} \cdot \mathrm{m}^{-2)}\right.$

$q_{i}$ - diffusive heat flux density $\left(\mathrm{W} \cdot \mathrm{m}^{-2}\right)$

$T$ - temperature $\left({ }^{\circ} \mathrm{C}\right)$

$u$ - gas velocity $\left(\mathrm{m} \cdot \mathrm{s}^{-1}\right)$

$\varepsilon$ - surface emissivity coefficient of thermal radiation (dimensionless)

$\lambda_{i}$ - eigenvalues of the thermal conductivity tensor $\left(\mathrm{W} \cdot \mathrm{m}^{-1} \cdot{ }^{\circ} \mathrm{C}^{-1}\right)$

$$
\begin{aligned}
& \Lambda \text { - thermal conductivity }\left(\mathrm{W} \cdot \mathrm{m}^{-1} \cdot{ }^{\circ} \mathrm{C}^{-1}\right) \\
& \mu-\text { dynamic viscosity coefficient }(\mathrm{Pa} \cdot \mathrm{s}) \\
& \mu_{t}-\text { turbulent eddy viscosity coefficient }(\mathrm{Pa} \cdot \mathrm{s}) \\
& \rho-\text { density }\left(\mathrm{kg} \cdot \mathrm{m}^{-3}\right) \\
& \sigma-\text { Stefan-Boltzmann constant }\left(\mathrm{W} \cdot \mathrm{m}^{-2} \cdot \mathrm{K}^{-4}\right) \\
& \tau_{i j}-\text { viscous shear stress tensor }(\mathrm{Pa})
\end{aligned}
$$

\section{Introduction}

The phenomenon of human thermal comfort is associated with many coefficients that characterize the human body, the environment where the human is, and his/her clothing. The main goal of clothing is to protect the human body against the negative effects of external factors and regulate the heat transfer between the human body and the environment. The heat exchange greatly depends on the geometric structure of the textile and the thermal properties of the raw materials from which the clothing is made. One of the parameters of clothing with a strong impact on the heat transfer between the human body and the environment is the thermal insulation [13]. This feature is one of the most important indicators of the value in use of textiles, especially for apparel woven fabrics, 
knitted fabrics, and technical fabrics, because it affects the physiological properties of clothing.

According to the literature, micro-computed tomography (micro-CT) has been used to provide detailed information on the geometry and geometric internal structure [3-7,9-12], as well as for simulation purposes $[8,11]$. Because of the complex structure of composites, micro-CT has been used by Huang et al. [4] to provide detailed information on the geometric mesostructure of continuous fiber composites to construct detailed geometric models of engineering textiles based on three-dimensional (3D) images. In another study [5], it has been used to characterize the microstructure of fabrics to acquire the input parameters for models of textiles and textile composites. Mikučioniene et al. [3] compare the mesoscopic internal structure of the fabric between the nondeformed state and a sheared state of woven fabrics. Chowdhury et al. [7] use micro-CT to nondestructively image, develop, and validate the structure-property relationships for textile carbon fiber polymers. A simulation based on finite element models obtained using the micro-CT is shown in another study [8]. $\mathrm{X}$-ray micro-CT has been used to characterize the 3D pore network and fibers inside glass wool [10]. In a study by Straumit et al. [11], the homogenized permeability of a noncrimp textile reinforcement material is computed using computational fluid dynamics (CFD) with voxel geometrical models. The models are constructed from $\mathrm{X}$-ray $\mathrm{CT}$ images using a statistical image segmentation method. In another report [12], X-ray micro-CT observations are used to understand and quantify the effect of the in-plane shear deformation of the composite reinforcement geometry at the meso-scale. Gliścińska et al. [13] applied optical coherence tomography image analysis to characterize the polymer surface layer in thermoplastic composite materials.

The work reported in the current article is related to the important problem of thermal comfort and is a continuation of the work on modeling physical phenomena related to the ergonomics of clothing [14-20]. In these related six articles, the physical properties of clothing textiles have been studied based on simulations of physical phenomena using 3D models of real textiles. These models were designed in the Solidworks computer-aided design (CAD) software based on real textiles' geometric parameters determined using scanning electron microscopy (SEM) images, which were analyzed using the ImageJ software. In the current study, the stage of designing
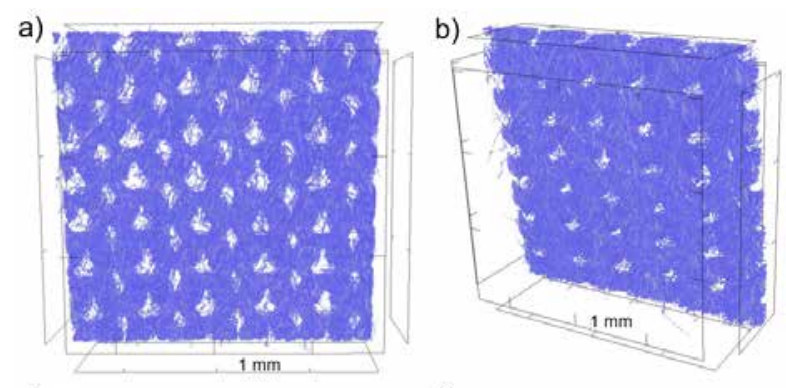

c)

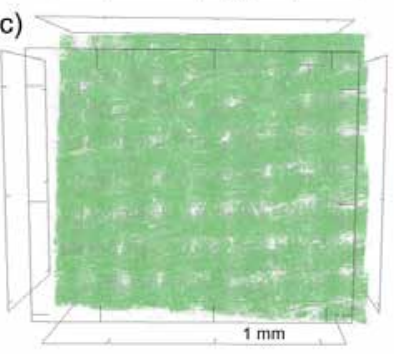

d)

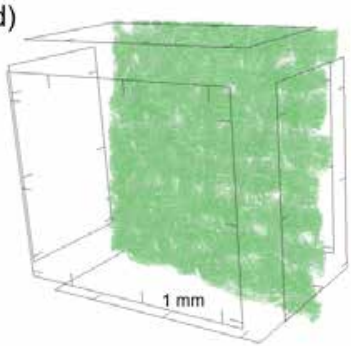

Figure 1. 3D images of the tested textiles ( $a$ and $b-$ knitted fabric; $c$ and $\mathrm{d}$ - woven fabric), obtained using micro-CT.

real textile models has been replaced by creating a model based on a $3 D$ reconstruction of the material using highresolution $\mathrm{X}$-ray micro-CT.

\section{Materials}

The subjects of this work were cotton knitted fabric with potential applications in multilayer garments for newborns and aramid woven fabric with potential applications in multilayer protective clothing for firefighters. The 3D images of both tested textiles were obtained using high-resolution X-ray micro-CT (SkySkan 1272 model, manufactured by Bruker, Kontich, Belgium), and these images are presented in Figure 1.

The tested knitted fabrics consist of only a sorptive cotton layer, which is excluded from direct contact with the skin of the newborn. The main role of this layer is to keep the moisture away from the body and vaporize it to the environment. The tested aramid woven fabric is an outer shell of the multilayer protective clothing for firefighters. Similar to any other layer, the outer shell is flame retardant and is responsible for protection against mechanical wear and tear. The characteristics of the tested textiles are presented in Table 1.

Table 1. Characteristics of the investigated textiles

\begin{tabular}{|c|c|c|c|c|c|c|c|c|}
\hline Textile & Weave & $\begin{array}{c}\text { Raw } \\
\text { material }\end{array}$ & $\begin{array}{c}\text { Layer } \\
\text { thickness }^{a} \\
(\mathrm{~mm})\end{array}$ & $\begin{array}{l}\text { Mass per unit } \\
\operatorname{area}^{\mathrm{b}}\left(\mathrm{g} \cdot \mathrm{m}^{-2}\right)\end{array}$ & $\begin{array}{c}\text { Porosity } \\
\text { (\%) }\end{array}$ & $\begin{array}{c}\text { Yarn } \\
\text { diameter } \\
\text { d }(\mathrm{mm})\end{array}$ & $\begin{array}{c}\text { Yarn } \\
\text { porosity }^{a} \\
(\%)\end{array}$ & $\begin{array}{c}\text { Fiber } \\
\text { diameter }^{\mathrm{a}} \\
(\mu \mathrm{m})\end{array}$ \\
\hline $\begin{array}{l}\text { Knitted } \\
\text { fabric }\end{array}$ & $\begin{array}{l}\text { Single } \\
\text { jersey }\end{array}$ & Cotton & 0.54 & 162.4 & 81 & 0.73 & 41 & 15 \\
\hline $\begin{array}{l}\text { Woven } \\
\text { fabric }\end{array}$ & Plain & Aramid & 0.48 & 200.4 & 70 & 0.52 & 44 & 24 \\
\hline
\end{tabular}

aBased on micro-CT images.

${ }^{\mathrm{b} A c c o r d i n g}$ to EN 12127 [21].

${ }^{\mathrm{c} A c c o r d i n g}$ to Equation 1 [22].

'Equivalent diameter, since the actual yarns did not have a circular cross section. 
For both tested textiles, the porosity $P$ was calculated according to Equation 1 [22].

$$
P=\left(1-\frac{M_{p} \cdot 10^{-3}}{d \cdot p}\right) \cdot 100 \%
$$

where $M_{p}$ is mass per unit area in grams per square meter $\left(\mathrm{g} \cdot \mathrm{m}^{-2}\right) ; d$ is thickness in millimeter $(\mathrm{mm})$; and $\rho$ is density of the raw material in grams per cubic centimeter $\left(\mathrm{g} \cdot \mathrm{cm}^{-3}\right)$.

\section{Methods}

In research described in earlier articles [14-20], the physical properties of clothing textiles were modeled using simulations of physical phenomena in 3D models of real textiles. These models were designed in the Solidworks CAD software based on the geometric parameters of actual textiles, determined using SEM images, which were analyzed with the ImageJ software (see "First approach of modeling" in Figure 2). In the current study, the stage of designing real textile models has been replaced by creating a model based on a $3 \mathrm{D}$ reconstruction using highresolution X-ray micro-CT (see "Second approach of modeling" in Figure 2). The knitted fabric model and woven fabric model obtained in this way were verified by measurements using a thermal imaging camera and real textiles (see "Experiment" in Figure 2).

\subsection{Modeling}

\subsubsection{Model design}

The first stage to obtain a 3D model of the tested textiles was the implementation of high-resolution micro-CT scans (X-ray source voltage: $50 \mathrm{kV}$, resolution: $4,032 \times 2,688$, pixel size $9 \mathrm{~mm}$, without filter, rotation step: $0.1^{\circ}$ ) and a 3D reconstruction using the NRecon software. Then, the reconstruction was transformed into a 3D model using the CTAn software. Finally, a)

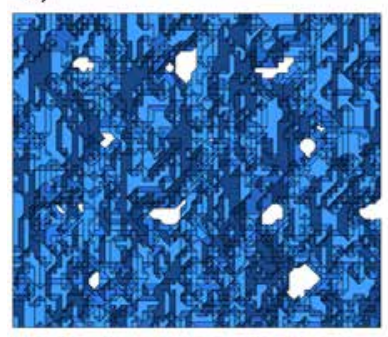

c)

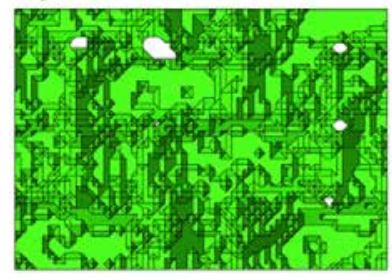

b)

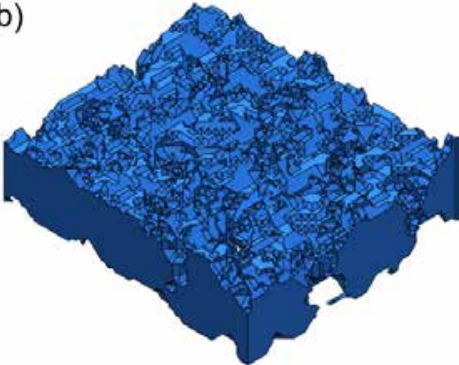

d)

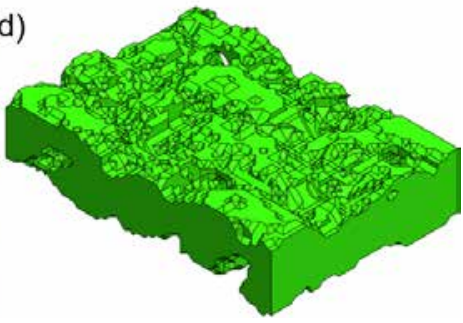

Figure 3. 3D models of tested textiles based on the micro-CT reconstructions ( $a$ and $b$ - cotton knitted fabric; $c$ and $d-$ aramid woven fabric).


Figure 2. Scheme of the textile thermal insulation modeling. 
the 3D models (Figure 3) were imported into the Solidworks Flow Simulation 2014 software for calculations of thermal insulation. The obtained textile models considered the geometry parameters of real cotton knitted fabric (layer thickness, loop shape, weave, yarn length in a single loop, and yarn diameter) and real aramid woven fabric (layer thickness, weave, size and shape of repeat, and yarn diameter).

\subsubsection{Simulations}

\subsubsection{Physical basis of the heat flow simulation: heat flow in} solids and gases

The Solidworks Flow Simulation 2014 software was used to model the heat transfer with the finite volume method. The applied software solves the energy conservation equations and the Navier-Stokes formulas [23, 24], which describe the fluid flow. This process enables one to estimate the simultaneous heat transfer in solid and fluid media and incorporates the energy exchange between these media. The equations are supplemented by fluid state equations, which define the nature of the fluid, and empirical dependencies of the fluid density, viscosity, and thermal conductivity on the temperature. The software can calculate temperature fields created by the following: (1) heat transfer in the solids (conduction); (2) free, forced, and mixed convection; and (3) radiation in both steady and transient states [23].

The two tested textiles (cotton knitted fabric and aramid woven fabric) were complex structures of fibers and had void spaces between fibers filled with air. In this type of material, heat is transported through the textile structure via both monofilaments (solid) and air (gas), with simultaneous exchange between these environments. The heat transfer in gases and liquids is expressed by the following conservation equation [23]:

$$
\frac{\partial}{\partial t}\left[\rho\left(h+\frac{u^{2}}{2}\right)\right]+\frac{\partial}{\partial x_{i}}\left[\rho u_{i}\left(h+\frac{u^{2}}{2}\right)\right]=\frac{\partial}{\partial x_{i}}\left[u_{j}\left(\tau_{i j}+\tau_{i j}^{R}\right)+q_{i}\right]+\frac{\partial p}{\partial t}-\tau_{i j}^{R} \frac{\partial u_{i j}}{\partial x_{j}}+\rho \varepsilon+S \mu_{i}+Q_{H}(2)
$$

where $\tau_{i j}$ is the viscous shear stress tensor defined as follows [23]:

$$
\tau_{i j}=\mu\left(\frac{\partial u_{i}}{\partial x_{j}}+\frac{\partial u_{j}}{\partial x_{i}}\right)
$$

where $\tau_{i j}^{R}$ is the Reynolds stress tensor defined as follows [23]:

$$
\tau_{i j}^{R}=\mu_{t}\left(\frac{\partial u_{i}}{\partial x_{j}}+\frac{\partial u_{j}}{\partial x_{i}}\right)
$$

$S_{i}=S_{i}^{\text {porous }}+S_{i}^{\text {gravity }}+S_{i}^{\text {rotation }}$ is the volume-distributed external force per unit volume [in newton per cubic meter $\left(\mathrm{N} \cdot \mathrm{m}^{-3}\right)$ ] due to the resistance of the porous media $\left(S_{i}^{\text {porous }}\right)$, buoyancy $\left(S_{i}^{\text {gravity }}=-\rho g_{i}\right)$, and rotation of the coordinate system $\left(S_{i}^{\text {rotation }}\right)$. The subscripts are used to denote a summation over the three coordinate directions.

The heat flux density is defined by the following equation [23]:

$$
q_{i}=\left(\frac{\mu}{P r}+\frac{\mu_{t}}{\sigma_{c}}\right) \frac{\partial h}{\partial x_{i}} ; i=1,2,3
$$

$$
\text { where } \mu_{t}=\frac{C_{\mu} \rho k^{2}}{\zeta}
$$

The constant $\mathrm{C} \mu$ is determined according to Solidworks [23] as being equal to $C \mu=0.09$, whereas $s c=0.9$. The equations describe both laminar and turbulent flows. Moreover, transitions from one case to another and back are possible; $k$ is the turbulence kinetic energy, and $\zeta$, in joules per kilogram per second $\left(\mathrm{J} \cdot \mathrm{kg}^{-1} \cdot \mathrm{s}^{-1}\right)$, is the turbulence dissipation (rate at which the turbulence kinetic energy is transformed into thermal internal energy). Parameters $k$ and $m t$ are zero in the case of pure laminar flows. The anisotropic heat conductivity in solid media is described by the following equation [23]:

$$
\frac{\partial(\rho e)}{\partial t}=\frac{\partial}{\partial x_{i}}\left(\lambda_{i} \frac{\partial T}{\partial x_{i}}\right)+Q_{H}
$$

where $e$ is the specific internal energy, $e=c T, c$ is specific heat, and $Q H$ is specific heat release (or absorption) per unit volume. The heat conductivity tensor is diagonal to the considered coordinate system, and the heat transport within the textile is independent of direction, i.e., we introduce an isotropic medium and can denote $11=12=13=\lambda$. The energy exchange between the gas and solid media is calculated via the heat flux in the direction normal to the solid-gas interface considering the solid surface's temperature and gas boundary layer characteristics if necessary [23].

\subsubsection{Physical basis of the heat flow simulation: thermal radiation}

The applied software enables the simulation of thermal radiation based on the so-called discrete transfer model. According to the model, the radiation that leaves the surface element in a certain range of solid angles can be approximated by a single ray. The radiation heat is transferred along a series of rays that only emanate from the radiative surfaces. Then, the rays are traced as they traverse through gas and transparent solid bodies until they hit another radiative surface. The thermal radiation from the surface or radiation source is expressed as a sum of the material radiation (described by the surface emissivity and prescribed area of radiation $A$ ) and incoming radiative transfer. This problem is defined as follows [23]:

$Q_{T}^{\text {out }}=\varepsilon \sigma T^{4} A+(1-\varepsilon) Q_{T}^{\text {in }}$

The main result from the calculation of the radiation heat transfer is the surface or internal temperature of the solid. However, these temperatures are also affected by heat conduction in solids and solid/gas heat transfer. To observe only the radiative heat transfer, the user can view the leaving radiant flux over the selected radiative surfaces in surface plots [23]. 
Table 2. Physical parameters of the raw materials used in the simulations [15, 16, 21]

\begin{tabular}{|c|c|c|c|}
\hline Physical parameter & Cotton & Aramid & Air \\
\hline Density $\left(\mathrm{kg} \cdot \mathrm{m}^{-3}\right)$ & 1,550 & 1,380 & 1.15 \\
\hline Specific heat $\left(\mathrm{J} \cdot \mathrm{kg}^{-1} \cdot{ }^{\circ} \mathrm{C}^{-1}\right)$ & 1,330 & 1,396 & 1,006 \\
\hline Thermal conductivity $\left(\mathrm{W} \cdot \mathrm{m}^{-1} \cdot{ }^{\circ} \mathrm{C}^{-1}\right)$ & 0.07 & 0.09 & 0.025 \\
\hline Emissivity & 0.78 & 0.65 & - \\
\hline
\end{tabular}

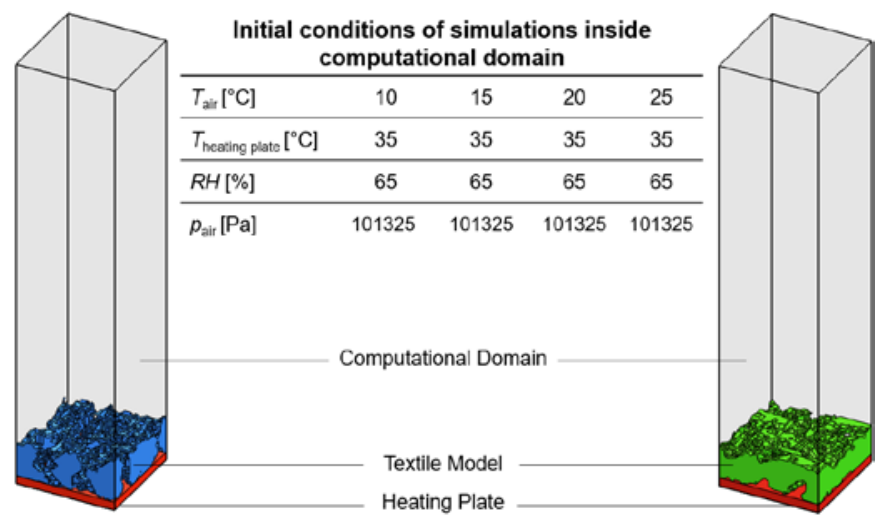

Figure 4. Initial conditions of the simulations inside the computational domain.

\subsubsection{Initial conditions of the simulations}

Simulations were performed with the SolidWorks Flow Simulation software using the finite volume method. The 3D models of the cotton knitted fabric and aramid woven fabric were reduced to the repetitive element due to their periodic structure and were placed on the top surface of a rectangular heating plate model. The appropriate raw material with the physical parameters in Table 2 was assigned to both geometry models of the examined textiles. Due to their complicated internal structure, the yarn in both tested textiles were mapped as the homogenized $3 \mathrm{D}$ solid objects with the respective physical parameters (density, specific heat, and thermal conductivity coefficient), which resulted from the yarn porosity shown in Table 1.

Both models of the tested textiles were positioned on the bottom of a rectangular computational domain filled with air. The domain height was approximately $5 \mathrm{~mm}$, and the sidewalls were tangential to the textile model. To eliminate the effects of the asymmetric boundary conditions, settings were applied to imitate an infinite layer of textile model that propagated outside of the domain in all four horizontal directions. The initial conditions of the simulation (Figure 4) in the computational domain imitated four ambient conditions of the verification experiment performed using a thermal imaging camera with real textiles $\left(T_{\text {air }}=10^{\circ} \mathrm{C}, R H=65 \%, p_{\text {air }}=101,325 \mathrm{~Pa} ; T_{\text {air }}=15^{\circ} \mathrm{C}, R H=65 \%\right.$, $p_{\text {air }}=101,325 \mathrm{~Pa} ; T_{\text {air }}=20^{\circ} \mathrm{C}, R H=65 \%, p_{\text {air }}=101,325 \mathrm{~Pa}$; and $T_{\text {air }}=25^{\circ} \mathrm{C}, R H=65 \%, p_{\text {air }}=101,325 \mathrm{~Pa}$ ). The temperature of the heating plate model was constant at $35^{\circ} \mathrm{C}$.

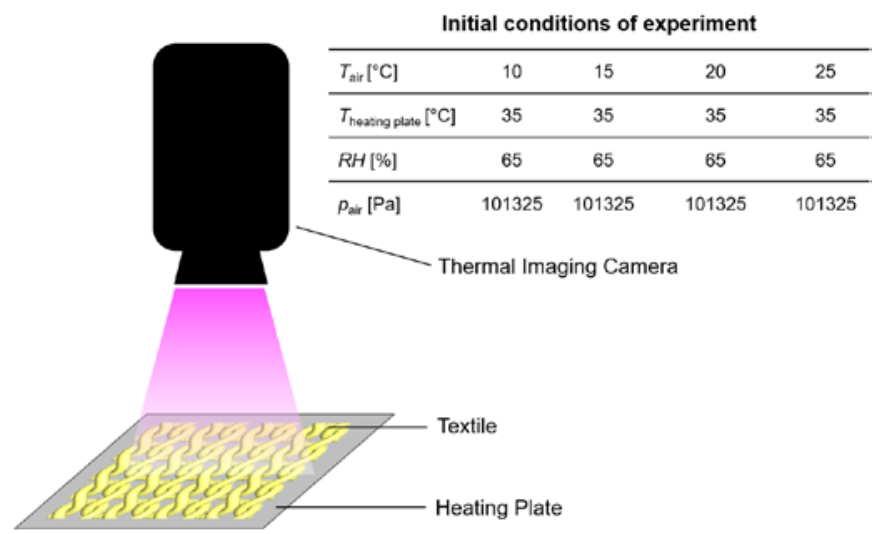

Figure 5. Scheme of the thermal imaging measurement.

The computational domain was divided into 37,894 cells (knitted fabric model) and 33,464 cells (woven fabric model) of three types (fluid cells, solid cells, and partial cells). The fluid cells were filled with air, while the solid cells had the material characteristics of the tested textile model, heating plate model, or both textile model and heating plate model. The partial cells contained both solid material and air.

\subsection{Thermography measurements}

To assess the thermal insulation of the tested textiles, the samples were placed in a room (Great Climatic Chamber made by Weiss Technik, Reiskirchen, Germany) with four selected constant ambient conditions $\left(T_{\text {air }}=10^{\circ} \mathrm{C}, R H=65 \% ; T_{\text {air }}=15^{\circ} \mathrm{C}\right.$, $R H=65 \% ; T_{\text {air }}=20^{\circ} \mathrm{C}, R H=65 \%$; and $T_{\text {air }}=25^{\circ} \mathrm{C}, R H=65 \%$ ) on a flat heating plate (Measurement Technology Northwest, Seattle, WA, USA) with a constant temperature $\left(T_{\text {plate }}=35^{\circ} \mathrm{C}\right)$. Using a thermal imaging camera (FLIR SC5000 model made in USA) and included software (Altair - Thermal Image Analysis Software), the average temperature of the top surface of the sample (facing the environment) $T_{\text {tex }}^{\text {av }}$ was measured. The scheme of the experiment is presented in Figure 5.

The temperature $T_{\text {tex }}^{\mathrm{av}}$ was measured for samples with an area of approximately $25 \mathrm{~cm}^{2}$, but the real sample size was larger (approximately $50 \mathrm{~cm}^{2}$ ) to reduce the negative effect of boundary conditions. Measurements were performed after reaching a steady state (approximately $10 \mathrm{~min}$ ). The measurement errors of the temperature, which resulted from the thermal imaging camera, were $\pm 1^{\circ} \mathrm{C}$. 


\section{Results and discussion}

The results of the measurements using a thermal imaging camera and simulations (Figure 8 and Table 3) showed a correlation between the tested textiles' thermal insulation property and the raw materials from which they were made. The simulation and measurement results show that the cotton knitted fabric is a better heat insulator than the aramid woven fabric. In Figure 8 and Table 3, the average temperatures of the top surface of the tested textiles $-T_{\text {tex }}^{\text {av }}$ - measured in the experiment and calculated by simulations at four ambient temperatures are presented. As expected, $T_{\text {tex }}^{\mathrm{av}}$ increases when the ambient temperature increases. For the cotton knitted fabric, the experimental $T_{\text {tex }}^{\mathrm{av}}$ increases from $31.91^{\circ} \mathrm{C}$ (for $T_{\text {air }}=10^{\circ} \mathrm{C}$ ) to $32.86^{\circ} \mathrm{C}$ (for $T_{\text {air }}=25^{\circ} \mathrm{C}$ ), while the simulated $T_{\text {tex }}^{\text {av }}$ increases from $32.59^{\circ} \mathrm{C}$ (for $T_{\text {air }}=10^{\circ} \mathrm{C}$ ) to $34.01^{\circ} \mathrm{C}$ (for $T_{\text {air }}=25^{\circ} \mathrm{C}$ ). The average temperature difference between the measured value in the experiment and the simulated value for the tested knitted fabric is $0.93^{\circ} \mathrm{C}$. In the case of aramid woven fabric, the experimental $T_{\text {tex }}^{\text {av }}$ increases from $32.99^{\circ} \mathrm{C}$ (for $T_{\text {air }}=10^{\circ} \mathrm{C}$ ) to $34.14^{\circ} \mathrm{C}$ (for $T_{\text {air }}=25^{\circ} \mathrm{C}$ ), while the simulated $T_{\text {tex }}^{\text {av }}$ increases from $34.07^{\circ} \mathrm{C}$ (for $T_{\text {air }}=10^{\circ} \mathrm{C}$ ) to $34.64^{\circ} \mathrm{C}$ (for $T_{\text {air }}=25^{\circ} \mathrm{C}$ ). The

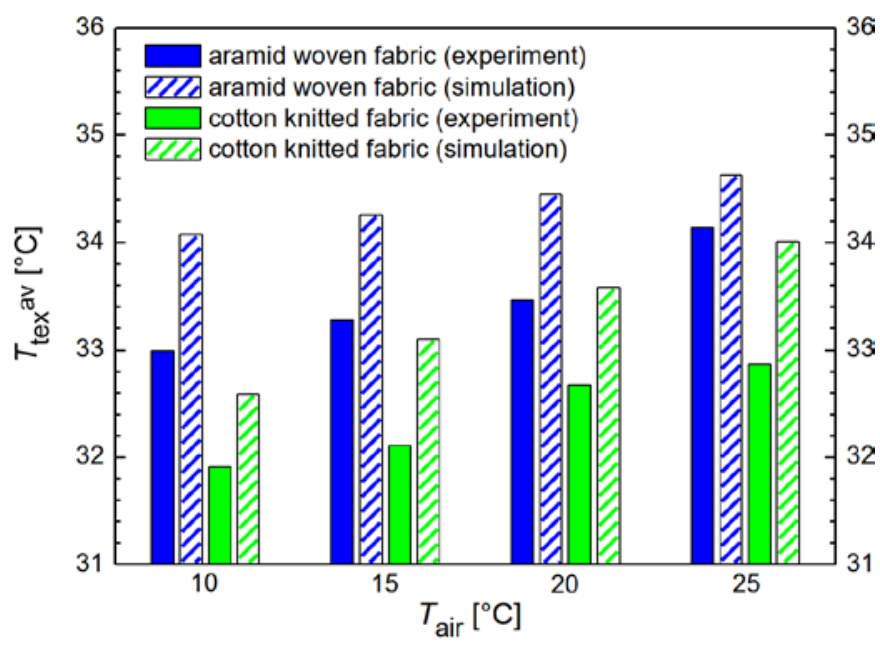

Figure 6. Average temperature of the top surface of the tested textiles determined in the experiment and calculated by simulations at four ambient temperatures. average temperature difference between the measured value in the experiment and the modeled value for the tested woven fabric is $0.89^{\circ} \mathrm{C}$. Therefore, the average difference between the measured and calculated temperatures $T_{\text {tex }}^{\text {av }}$ for both tested textiles is below the uncertainty of measurement with a thermal imaging camera $\left( \pm 1^{\circ} \mathrm{C}\right)$. The narrower temperature increase for the tested woven fabrics can be the result of three key issues: the woven fabric is $0.06 \mathrm{~mm}$ thinner than the knitted fabric, the woven fabric is $11 \%$ less porous than the knitted fabric, and aramid has a higher thermal conductivity coefficient (by $\left.0.02 \mathrm{~W} \cdot \mathrm{m}^{-1 .}{ }^{\circ} \mathrm{C}^{-1}\right)$ than cotton.

For both tests, the simulated temperature for all ambient temperatures is higher than the corresponding temperature measured in the experiment. This repeated difference between the experiment and simulation results $(2.13 \%-3.50 \%$ for cotton knitted fabric and $1.44 \%-3.27 \%$ for aramid woven fabric) may be due to several independent problems related to both modeling and measurement.

First, the 3D models of the tested textiles were created based on reconstruction using the micro-CT images and reduced to the volume of the repetitive element of the perfectly periodic structure of the tested textiles; there is, in fact, no ideal periodic structure (in any real knitted fabric or woven fabric). Moreover, the model based on a very accurate reconstruction has some simplifications in relation to the actual form of the material. The designed models of both tested textiles accurately reproduced most of the geometrical parameters of real textiles, such as the layer thickness, weave, and shape of yarn, but did not consider the free spaces among the fibers in the yarn, which are filled with air (better thermal insulator than cotton and aramid). The applied homogenization of aramid with air in the yarn of the fabric model and homogenization of cotton with air in the yarn of the knitted model could have been too simplified for the yarn model in relation to the actual structure of the yarn in both examined textiles. These simplifications may have affected the temperature distribution patterns in the textile models under different ambient conditions (Figure 7).

Meanwhile, the differences between the simulation and the experimental results may originate from the measurement



Figure 7. Temperature distributions in the 3D models of the tested textiles for four different ambient temperatures. 
Table 3. Temperature (minimum, average, and maximum) of the top surface of the tested textiles determined in the experiment and calculated by simulations at four ambient temperatures

\begin{tabular}{|c|c|c|c|c|c|c|c|c|c|}
\hline \multicolumn{2}{|c|}{ Ambient conditions } & \multirow{3}{*}{ Textile } & \multicolumn{3}{|c|}{$\begin{array}{c}\text { Experiment } \\
\text { (based on thermography) }\end{array}$} & \multicolumn{3}{|c|}{$\begin{array}{c}\text { Simulations } \\
\text { (based on CT textile model) }\end{array}$} & \multirow{3}{*}{$T_{\mathrm{tex}}^{\mathrm{av}}\left({ }^{\circ} \mathrm{C}\right)$} \\
\hline & & & \multirow[b]{2}{*}{$T_{\text {tex }}^{\min }\left({ }^{\circ} \mathrm{C}\right)$} & \multirow[b]{2}{*}{$T_{\text {tex }}^{\text {av }}\left({ }^{\circ} \mathrm{C}\right)$} & \multirow[b]{2}{*}{$T_{\text {tex }}^{\max }\left({ }^{\circ} \mathrm{C}\right)$} & \multirow[b]{2}{*}{$T_{\text {tex }}^{\min }\left({ }^{\circ} \mathrm{C}\right)$} & \multirow[b]{2}{*}{$T_{\mathrm{tex}}^{\mathrm{av}}\left({ }^{\circ} \mathrm{C}\right)$} & \multirow[b]{2}{*}{$T_{\mathrm{tex}}^{\max }\left({ }^{\circ} \mathrm{C}\right)$} & \\
\hline$T_{\text {air }}\left({ }^{\circ} \mathrm{C}\right)$ & $R H(\%)$ & & & & & & & & \\
\hline 10 & 65 & \multirow{4}{*}{$\begin{array}{c}\text { Cotton } \\
\text { knitted } \\
\text { fabric }\end{array}$} & 31.52 & 31.91 & 33.91 & 32.35 & 32.59 & 32.65 & 0.68 \\
\hline 15 & 65 & & 31.75 & 32.11 & 34.34 & 32.73 & 33.10 & 33.24 & 0.99 \\
\hline 20 & 65 & & 32.26 & 32.67 & 34.50 & 33.37 & 33.58 & 33.72 & 0.91 \\
\hline 25 & 65 & & 32.35 & 32.86 & 34.56 & 33.71 & 34.01 & 34.20 & 1.15 \\
\hline 10 & 65 & \multirow{4}{*}{$\begin{array}{c}\text { Aramid } \\
\text { woven } \\
\text { fabric }\end{array}$} & 32.02 & 32.99 & 33.14 & 33.89 & 34.07 & 34.28 & 1.08 \\
\hline 15 & 65 & & 32.49 & 33.28 & 33.91 & 33.96 & 34.26 & 34.45 & 0.98 \\
\hline 20 & 65 & & 33.18 & 33.46 & 34.04 & 34.24 & 34.45 & 34.67 & 0.99 \\
\hline 25 & 65 & & 33.20 & 34.14 & 34.81 & 34.41 & 34.63 & 34.82 & 0.49 \\
\hline
\end{tabular}
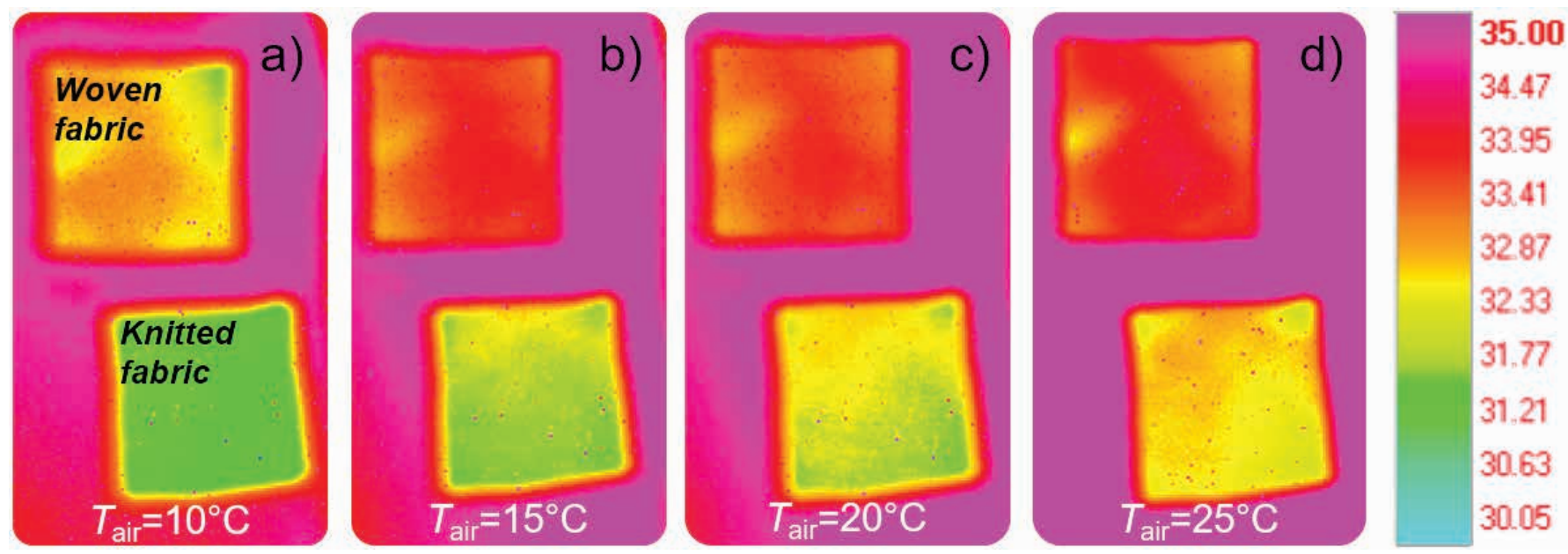

Figure 8. Temperature distributions on the outer surfaces of the aramid woven fabric (top) and cotton knitted fabric (bottom) for four selected ambient temperatures $\left(10^{\circ} \mathrm{C}, 15^{\circ} \mathrm{C}, 20^{\circ} \mathrm{C}\right.$, and $\left.25^{\circ} \mathrm{C}\right)$ using a thermal imaging camera.

using a thermal imaging camera. To perform the measurement under identical ambient conditions, the measurement was simultaneously taken with the same camera for both textiles.

Cotton and aramid have different emissivity values, 0.78 and 0.65 , respectively. To make a simultaneous objective measurement for the cotton knitted fabric and aramid woven fabric, an average emissivity value of 0.72 was used. The need to take the average value could have affected the temperature distributions for different ambient conditions using thermography, as presented in Figure 8.

\section{Conclusions}

In this paper, the new method of applying high-resolution $\mathrm{X}$-ray micro-CT to model the thermal insulation of textiles was presented. Based on the 3D images obtained with the micro-CT, two 3D models of textiles used in functional clothing, namely, cotton knitted fabric and aramid woven fabric, were developed. The designed models mapped both geometry and raw material composition of the real textiles. The models were used to simulate the heat transport using the finite volume method to calculate their thermal insulation under four selected ambient conditions. The results of modeling the thermal insulation of the tested materials were verified by an experiment with real textiles using thermography in identical ambient conditions.

The experimental measurements correlated with the simulated predictions, and the differences between them varied depending on the specific parameters and ambient conditions. These differences may be related to modeling issues concerning all simplifications in relation to the complicated geometry of real textiles, as follows:

Homogenization - instead of considering individual fibers in the models and spaces among them, which are filled with air - in the models of the cotton knitted fabric and aramid woven fabrics (the actual porosity is not isotropic),

The developed models of the cotton knitted fabric and aramid woven fabric - due to their periodic structure - were reduced to the repetitive element when copied in all four horizontal directions to create the entire textile, whereas the real knitted 
and woven fabrics never have two identical structural elements despite their periodic structure.

Despite the aforementioned simplifications, the presented method and developed micro-CT-based models of the tested textiles allow one to predict the thermal insulations with an error of $2.13 \%-3.50 \%$ for cotton knitted fabric and $1.44 \%-3.27 \%$ for aramid woven fabric. The presented results of the CFD simulations are verified by the results of the experiment using thermography on real materials. Thus, the method used herein can be useful for understanding and optimizing the thermal protection and comfort properties of functional clothing.

\section{Acknowledaments}

These studies were financed from funds assigned from 142/501/14-148-1-19 statutory activity by the Lodz University of Technology, Institute of Material Science of Textiles and Polymer Composites, Poland; and the "Innovative Textiles 2020+" investment project within the Regional Operational Programme for Łódzkie 2014-2020.

\section{References}

[1] Ziaei, M., Ghane, M., Hasani, H., Saboonchi, A. (2019). Simulation of Temperature distribution within weft-knitted fabrics in extended state. Clothing and Textiles Research Journal. DOI: $10.1177 / 0887302 \times 19856112$.

[2]. Buzaite, V., Repon, R. M. D., Milasiene, D., Mikucioniene, D. (2019). Development of multi-layered weft-knitted fabrics for thermal insulation. Journal of Industrial Textiles, 88(14). DOI: 10.1177/1528083719878811.

[3]. Mikučioniene, D., Čepukone, L., Milašiene, D. (2017). Investigation on mechanical and thermal properties of knits from peat fibers and their combination with other natural fibers. Textile Research Journal, 88(14), 1660-1670.

[4] Huang, W., Causse, P., Brailovski, V., Hu, H., Trochu, F. (2019). Reconstruction of mesostructural material twin models of engineering textiles based on Micro-CT aided geometric modeling. Composites Part A: Applied Science and Manufacturing, 124, 105481.

[5] Desplentere, F., Lomov, S. V., Woerdeman, D. L., Verpoest, I., Wevers, M., et al. (2005). Micro-CT characterization of variability in $3 D$ textile architecture. Composites Science and Technology, 65(13), 1920-1930.

[6] Barburski, M., Straumit, I., Zhang, X., Wevers, M., Lomov, S. V. (2015). Micro-CT analysis of internal structure of sheared textile composite reinforcement. Composites Part A: Applied Science and Manufacturing, 73, 45-54.

[7] Chowdhury, N. T., Tao, C., Pearce, G.M., Walsh, S. D. C., Latham, S. J., et al. (2019). Design of an uncontaminated textile CFRP specimen optimised for both mechanical testing and X-ray microtomography. Composites Part A: Applied Science and Manufacturing, 123, 208-221.

[8] Vanaerschot, A., Panerai, F., Cassell, A., Lomov, S. V., Vandepitte, D., et al. (2017). Stochastic characterisation methodology for 3-D textiles based on micro-tomography. Composite Structures, 173, 44-52.

[9] Meftah, R., Berger, S., Jacqus, G., Laluet, J.-Y., Cnudde, $V$. (2019). Multiscale characterization of glass wools using X-ray micro-CT. Materials Characterization, 156, 109852.
[10] Straumit, I., Hahn, Ch., Winterstein, E., Plank, B., Lomov, S. V., et al. (2016). Computation of permeability of a non-crimp carbon textile reinforcement based on X-ray computed tomography images. Composites Part A: Applied Science and Manufacturing, 81, 289-295.

[11] Pazmino, J., Carvelli, V., Lomov, S. V. (2014). Micro-CT analysis of the internal deformed geometry of a non-crimp $3 D$ orthogonal weave E-glass composite reinforcement. Composites Part B: Engineering, 65, 147-157.

[12] Sinchuk, Y., Pannier, Y., Antoranz-Gonzalez, R., Gigliotti, $M$. (2019). Analysis of moisture diffusion induced stress in carbon/epoxy $3 D$ textile composite materials with voids by $\mu$-CT based Finite Element Models. Composite Structures, 212, 561-570.

[13] Gliścińska, E., Sankowski, D., Krucińska, I., Gocławski, J., Michalak, M., et al. (2017).. Optical coherence tomography image analysis of polymer surface layers in soundabsorbing fibrous composite materials. Polymer Testing, 63, 194-203.

[14] Puszkarz, A. K., Korycki, R., Krucinska, I. (2015). Simulations of heat transport phenomena in a threedimensional model of knitted fabric. Autex Research Journal, 16(3), 128-137. DOI: 10.1515/aut-2015-0042 (CAUTEX.

[15] Puszkarz, A. K., Krucińska, I. (2016). Study of multilayer clothing thermal insulation using thermography and the finite volume method. Fibres and Textiles in Eastern Europe, 24 6(120), 129-137.

[16] Puszkarz, A. K., Krucińska, I. (2017). The study of knitted fabric thermal insulation using thermography and finite volume method. Textile Research Journal, 87(6), 643-656.

[17] Puszkarz, A. K., Krucińska, I. (2018). Modeling of air permeability of knitted fabric using the computational fluid dynamics. Autex Research Journal, 18(4), 364-376 DOI: 10.1515/aut-2018-0007 @ AUTEX.

[18] Puszkarz, A. K., Krucińska, I. (2018). Simulations of air permeability of multilayer textiles by the computational fluid dynamics. International Journal for Multiscale Computational Engineering, 16(6), 509-526.

[19] Puszkarz, A. K., Usupov, A. (2019). The study of footwear thermal insulation using thermography and finite volume method. International Journal of Thermophysics, 40, 45. DOI: 10.1007/s10765-019-2509-1.

[20] Puszkarz, A. K., Machnowski, W., Błasińska, A. (2020) Modeling of thermal performance of multilayer protective clothing exposed to radiant heat. Heat and Mass Transfer. DOI: 10.1007/s00231-020-02820-1.

[21] EN 12127. Textiles - Fabrics - Determination of mass per unit area using small samples.

[22] Pietrzak, K., Gutarowska, B., Machnowski, W., Mikołajczyk, U. (2015) Antimicrobial properties of silver nanoparticles misting on cotton fabrics. Textile Research Journal, 86(8), 812-822. DOI: 10.1177/0040517515596933.

[23] SolidWorks Flow Simulation - Technical Reference 2014.

[24] Jiang, N., Mohebujjaman, M., Rebholz, L. G., Trenchea, C. (2016). An optimally accurate discrete regularization for second order timestepping methods for Navier-Stokes equations. Computer Methods in Applied Mechanics and Engineering, 310, 388-405.

[25] Web site: https://www.engineeringtoolbox.com (accessed: 31 October 2019). 